\title{
Reconhecimento e subjugação: da relacão entre teorias positivas e negativas da intersubjetividade
}

\section{Resumo}

O texto se ocupa da relação entre reconhecimento e subjugação, das teorias negativas e positivas do reconhecimento. Ponto de partida comum dessas teorias é a percepção do caráter relacional de nossa identidade e a interpretação desta relação e dependência como um acontecimento constitutivo e produtivo. Em minha estratégia argumentativa, procederei de modo "interno": tomarei a sério a circunstância de que, nos dois casos, tratem-se de teorias da intersubjetividade para avaliar se fazem ou não justiça à percepção original de que a consciência de mim mesmo eu só adquiro mediada por outra autoconsciência. As duas posições compartilham da concepção segundo a qual não existe um self pré-social e, com isso, compartilham também a concepção de que individualidade e sociabilidade se condicionam reciprocamente. Mas elas se distinguem no modo como interpretam e avaliam esta circunstância.

Palavras-Chave: Teoria do reconhecimento. Intersubjetividade. Individualidade e sociabilidade. Axel Honneth.

*Filósofa. Professora no Instituto de Filosofia da Universidade Humboldt, em Berlim (Alemanha).E-mail: rahel.jaeggi@staff.hu-berlin.de. 


\section{Recognition and subjugation: on the relationship between positive and negative theories of intersubjectivity ${ }^{1}$}

\section{Abstract}

This paper deals with the relationship between recognition and subjugation as approached in the negative and positive theories of recognition. A common starting point of these theories is the perception of the relational character of our identity and the interpretation of this dependency relation as a productive and constitutive event. In my argumentative strategy, I will proceed in an "inward" manner: I will take seriously the fact that, in both cases, theories of intersubjectivity are treated to assess whether or not they do justice to the original perception that consciousness of myself I only acquire as mediated by another self. The two positions share the conception that there is no pre-social self and, thus, also share the view that individuality and sociality are mutually conditioning. They, nevertheless, differ as to how they interpret and evaluate this condition.

Keywords: Theory of recognition. Intersubjectivity. Individuality and sociability. Axel Honneth.

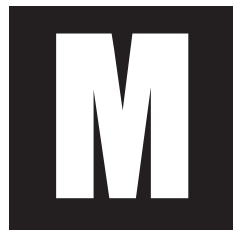

eu texto se ocupa da relação entre reconhecimento e subjugação; mais exatamente: ele discute a tese segundo a qual relações intersubjetivas de reconhecimento, bem distantes de serem unicamente a condição positiva de possibilidade para uma autorrelação bem sucedida, possam também ser compreendidas como reificação e limitação, como identificação congelante e adscrição opressora e, com isso, como relação sutil de dominação e apoderamento. Trata, portanto, da tese de que relações de reconhecimento implicariam em um duplo caráter de possibilitação e subjugação do sujeito (cf. Saar, 2004), um tema que une propostas

\footnotetext{
${ }^{1}$ Tradução do alemão: Emil A. Sobottka.
} 
tão distintas como as de Sartre, Althusser e Judith Butler. Dito de modo mais amplo, nesta pergunta se revela uma tensão entre teorias "negativas" e "positivas" da intersubjetividade. Esta tensão não perpassa apenas a discussão contemporânea; ela já influenciou, em vários sentidos, aquilo que se pode interpretar como a "sobrevida" do conceito hegeliano de reconhecimento assim como sua "vida pregressa" (a saber, em Rousseau)2.

Dentro do campo de conflito assim esboçado, minha estratégia de argumentação neste texto procederá de modo "interno": tomarei a sério a circunstância de que, nos dois casos - seja com conotação positiva ou negativa -, tratem-se de teorias da intersubjetividade, e que, portanto, as duas interpretações do acontecimento de reconhecimento têm um ponto de partida em comum. Tendo como pano de fundo essa base comum, as diferentes interpretações do reconhecimento devem ser avaliadas segundo façam ou não justiça à "percepção original" sobre a constituição intersubjetiva da autorrelação, do fato que a consciência de mim mesmo eu somente adquiro mediada por outra autoconsciência. Argumentarei que a tese do reconhecimento como reificação e subjugação não se atém ao seu próprio ponto de partida teórico, na medida em que ela, contra sua vontade, ao fim e ao cabo, resulta em um romantismo da autenticidade pré-social. Minha crítica é que, desse modo, não apenas se "exacerba", até certo ponto, a compreensão de subjugação e nivela-se a diferença entre os problemáticos fenômenos de reificação e apoderamento de um lado e processos não problemáticos da determinação social de outro; com essa postura, justamente, se obstrui uma compreensão adequada da relação tensa (tão insuperável quanto conflitiva) entre indivíduo e sociedade.

${ }^{2}$ Sobre a teoria do reconhecimento por assim dizer avant la lettre em Rousseau, ver o excelente estudo de Neuhouser (2008). 
No que segue destacarei, num primeiro passo, o que as teorias positivas e negativas da intersubjetividade têm em comum, para, num segundo passo, realçar suas diferenças. No terceiro passo farei a crítica da postura negativa para, finalmente, no quarto passo, esboçar uma versão da tese da origem simultânea da individualização e da socialização que, não obstante concebida como uma relação tensa, não se torna trágico-aporética.

1 A percepção original: a sociabilidade do self e a relação de intersubjetividade

A "percepção original", o diagnóstico inicial comum das teorias do reconhecimento intersubjetivo, é a seguinte: se o reconhecimento puder ser compreendido como ato interpessoal de identificação e afirmação de uma pessoa (ou de alguns de seus atributos), então essas teorias partem fundamentalmente da convicção de que, como Mead (1991, p. 430) o formula, nós somos o que somos através de outros e, por conseguinte, como sujeitos dependemos fundamentalmente (e em sentido que ultrapassa a compreensão instrumental) da sociabilidade e da interação com outros.

Tanto a variante positiva como a negativa compartilham os seguintes pressupostos:

a) A percepção da dependência e relacionalidade fundamental, ou seja, de que os seres humanos não crescem como os cogumelos hobbesianos na floresta (cf. Hobbes, 1994, p. 161), mas se encontram como sujeitos numa trama de relações recíprocas de reconhecimento, que é simultaneamente uma trama de dependência recíproca. Nesse sentido, o "self" é totalmente "relacional", como self sempre já dentro de relações e só compreensível a partir delas. 
b) Se, portanto, a identidade não é algo simplesmente dado, mas algo que primeiro deve constituir-se (justamente em processos de reconhecimento), segue-se, então, que não há um "interior", um "próprio"que pudesse subsistir sem a mediação do "externo", dos outros e das exigências colocadas com a inserção em relações sociais. Aquilo que é reconhecido se constitui, em sentido decisivo, somente no ato do reconhecimento. Através disso, aquilo que acima denominei relacionalidade do self torna-se radical: não é o indivíduo já pronto que estabelece relação (de reconhecimento). Justamente por isso o acontecimento do reconhecimento é tão fundamental. E precisamente por isso se depende de reconhecimento em um sentido que vai além do instrumental.

c) Se a percepção essencial da(s) teoria(s) do reconhecimento ou da intersubjetividade for aquela do caráter relacional e mediador das relações dos seres humanos consigo e com o mundo, então deverse-ia tomar a sério o discurso sobre a "relação": uma relação é um relacionamento entre separados que, ao mesmo tempo, estão referidos entre si. Para a relação de reconhecimento, segue-se que com ela não se designa desde já uma unidade, tampouco uma situação de separação e estranheza, no sentido de ser-reciprocamente-indiferente. O fato de que, na "luta por reconhecimento" hegeliana, a relação de dependência e independência primeiro necessita ser sondada expressa esse caráter relacional: ela estabelece a relação enquanto disputa. 


\section{Duas interpretações da relação de reconhecimento: teorias positivas e negativas da intersubjetividade}

Quais são, pois, as diferenças na interpretação? Em que se distinguem as teorias positivas das teorias negativas da intersubjetividade? Deixando de lado diferenças internas, é possível distinguir dois ramos teóricos como segue ${ }^{3}$ :

a) as teorias positivas da intersubjetividade: nesse caso (de Fichte e Hegel até Habermas, Taylor e Honneth), a circunstância de que sejamos dependentes do reconhecimento de outros para poder constituir-nos em nossa autorrelação é tratado positivamente. O fato de nosso envolvimento constitutivo-necessário em relações de reconhecimento é compreendido aqui como afirmação e adscrição positiva de atributos, que ajuda o reconhecido a chegar a uma referência positiva com a própria identidade e com isso se torna uma das condições de possibilidade de sua liberdade e de suas possibilidades de ação.

Tipicamente, o fato do reconhecimento é então interpretado de modo que nele está o potencial normativo do reconhecimento recíprocosimétrico quando não até o seu telos inerente. Reconhecimento só funciona como reconhecimento recíproco. A famosa fórmula hegeliana do reconhecer como reconhecendo-se reciprocamente (Hegel, 1970, p. 147) torna-se, assim, o código da sociabilidade bem-sucedida. O foco central da argumentação é que esta reciprocidade não é introduzida por Hegel como uma exigência moral, mas, de certo modo, como necessidade funcional. Assim, não é que eu deva reconhecer o outro como homólogo de igual valor, devido a razões morais que, por seu turno, fossem exteriores

\footnotetext{
${ }^{3}$ Numa exposição muito instrutiva na perspectiva da teoria social, Robin Celikates (2007) descreve esses dois ramos como relacionados à "teoria do conflito" versus à "teoria da reconciliação".
} 
ao processo de reconhecimento. Eu necessito reconhecê-lo, para que eu mesmo possa ser reconhecido (por ele). Dito genericamente, isso se deve a que, como autônomo, não é possível deixar-se reconhecer por um objeto, um heterônomo. E é isso que perfaz a complexidade e a dinâmica da luta por reconhecimento (na versão hegeliana), cuja dinâmica profunda sequer seria posta em marcha sem a exigência da reciprocidade. Isto é, sob um aspecto decisivo, reconhecimento assimétrico não é reconhecimento; ele é deficitário num sentido que insta à superação desse déficit ${ }^{4}$.

b) teorias negativas da intersubjetividade: no outro caso (uma linha que vai de Sartre e Althusser até Butler), o mesmo ponto de partida é interpretado de modo distinto: o fato de serem os outros (o reconhecimento, o olhar, a interpelação pelo outro, a inserção numa ordem simbólica) que nos tornam aquilo que somos é visto nas distintas versões desta tradição (mesmo que nem sempre exatamente com essa terminologia) como constitutivamente reificante. $\mathrm{O}$ fato de que só alcançamos nossa identidade na medida em que nos referimos a outros e os outros a nós é visto aqui (exemplarmente em Sartre) como concomitante com a destituição de nossa liberdade ou (como em Althusser e Butler) com a vinculação indefesa ao poder (reconhecedor), do qual dependemos - uma dependência na qual, segundo Butler (2001, p. 32), se revela uma alienação primária e inaugural no social. Nessa tradição, a relação de reconhecimento, mesmo onde ela parece inevitável, é interpretada como relação de alienação, opressão e dominação. Consequentemente, nessa linha de interpretação, o reconhecimento é descrito sempre como funda-

\footnotetext{
${ }^{4}$ Ressalte-se que não é que os hegelianos não percebam as assimetrias; elas tornam-se até mesmo no momento impulsionador, mas na perspectiva de sua superação tanto factual como normativa (cf. Honneth, 1994, p. 28, 31, passim).
} 
mentalmente assimétrico. De modo correspondente, apresentamse as cenas características nas quais, segundo esta interpretação, se manifesta o acontecimento do reconhecimento:

- Através de sua interpelação (Ei, você aí, alto lá!), o policial (Althusser, 1977 , p. 142) transforma o homem na rua em "alguém" e no mesmo momento o subjuga;

- O "outro" (na famosa análise do olhar de O ser e o nada, de Sartre) surpreende o curioso ou ciumento enquanto esse espia pelo buraco da fechadura para observar ${ }^{5}$ um acontecimento que lhe é ocultado e, com isso, reifica-o como objeto.

Estas são as imagens originárias de um reconhecimento que se apresenta como subjugação e reificação. Nestes casos, o reconhecimento nunca é recíproco; ele se caracteriza por um desnível de poder e constitui esse desnível. O reconhecimento, quando assim concebido, é constitutivamente assimétrico. $\mathrm{O}$ outro que me surpreende espiando pelo buraco da fechadura e, com isso, mediado pelo sentimento de vergonha que por si já me assola, me constitui (dolorosa, penosamente) em sujeito consciente de si próprio, me domina com ou através deste ato. Desse status de objeto que acompanha a relação intersubjetiva de reconhecimento em Sartre, só é possível livrar-se ao, inversamente, tornar agora o outro em objeto, e isso significa tomar por objetivo, por seu turno, apoderar-se dele. Se aqui existir uma reciprocidade, será, então, unicamente aquela da reificação e da subjugação recíprocas, uma relação que, vista com olhos hegelianos, permanece necessariamente aporética.

\footnotetext{
${ }^{5}$ Refiro-me aqui ao famoso exemplo central da "Análise do olhar", na qual Sartre (1994) faz uma descrição fenomenológica impressionante da força constitutiva do olhar, recorrendo ao ciumento que é flagrado ao espiar pelo buraco da fechadura.
} 
Embora, também, nessas descrições, o reconhecimento seja uma forma de possibilitação - afinal, antes da interpelação eu não sou sujeito; eu só me torno consciente de mim mesmo através do observador da cena do buraco da fechadura. Essa possibilitação, contudo, é perpassada por uma profunda ambivalência: ela significa, ao mesmo tempo, limitação, subjugação e impedimento de minha liberdade; uma ambivalência da qual, como melancolicamente o diz Judith Butler (2001, p. 184), não há saída. Portanto, a relação de reconhecimento parece destinada, por princípio, ao fracasso. Coerentemente, reconhecimento que menospreza (Bedorf, 2010) é uma das formulações para expressar os efeitos negativos de um reconhecimento que, repetida e necessariamente, desconhece o outro.

Mas o que precisamente perfaz o caráter de dominação do reconhecimento segundo as teorias negativas? Como se distingue a estrutura interna de relação de reconhecimento nas duas interpretações? Dito de um modo mais amplo: aqui estão em operação diferentes interpretações, não apenas da dependência constitutiva das relações de reconhecimento, mas também daquilo que é inerente a todas relações de reconhecimento como capacidade de determinação. Enquanto o procedimento no qual eu reconheço alguém como algo contém sempre um momento da identificação e da determinação (a saber, de alguém como algo), as diferentes interpretações deste procedimento parecem se distinguir essencialmente no modo como elas interpretam essa determinação e o "ser determinado como algo" dela resultante.

O procedimento no qual alguém é determinado como algo, ao mesmo tempo, pode ser concebido no sentido de que aqui alguém é determinado para algo e, ao fim e ao cabo, que com isso seja feita uma determinação sobre ele. Pela determinação do reconhecido como algo ocorre a determinação sobre ele. Como diz Heidegger (1963, p. 127), ele acaba sob a subserviência do outro. E é precisamente essa circunstância que 
as teorias negativas do reconhecimento enfocam. A palavra chave correspondente já foi dita: o reconhecimento, segundo essa interpretação, se efetiva como reificação objetivante - e, precisamente por isso, como dominação e subjugação ${ }^{6}$.

Nesse contexto vale a pena diferenciar entre duas dimensões: por um lado o reconhecimento é objetificante, por outro ele é uniformizador.

a) reconhecimento tem efeito fixador/petrificante: o olhar do outro nos "fixa" de modo objetificante. Apanhado ao espiar-pelo-buracoda-fechadura, eu agora sou o ciumento, o curioso, eu sou - na opinião/ segundo a adscrição dos outros - uma alemã branca (ou não), uma boa mãe (ou não), uma cientista (ou não exatamente). Se - na terminologia de Sartre - o "ser-para-si" do sujeito se caracterizar pela "transcendência", porque, como um "autoprojeto", está voltado a um horizonte aberto de possibilidades, então nós somos reificados na medida em que - tal como objetos - somos fixados em nossa "efetividade". Se o olhar do outro em Sartre significa a solidificação e a alienação de minhas próprias possibilidades ou até, como Sartre (1994, p. 474) o exprime dramaticamente, sua "morte", então se trata de uma determinada interpretação da circunstância de que nós aqui somos determinados para e como algo, e que, ao mesmo tempo, não temos o poder para determinar para que e como somos determinados (Sartre, 1994, p. 477).

b) no entanto, sobretudo a partir de Althusser, o olhar recai sobre uma dimensão mais "profunda": reconhecimento tem um efeito uniformizador. A "interpelação" pelo policial não apenas fixa alguém como algo (em seu ser assim). O efeito mais fundamental (por Althusser denominado "ideológico") dessa interpelação-reconhecedora é que, por

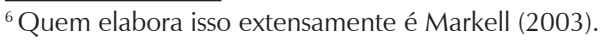


ela, é afirmada uma unicidade fictícia de algo que "por si só" não tem unidade. A identidade (e o indivíduo) em sentido literal só aqui é constituída como a circunstância do ser-uno-consigo-mesmo e do "ser-uno". $\mathrm{E}$, porque constantemente fracassa com sua própria matéria, ela necessita usar da violência - assim, pelo menos, Butler (2007, p. 60) descreve o processo pelo qual momentos psíquicos necessariamente díspares e ambivalentes frente às reivindicações dos outros são incluídos à força num construto autobiográfico.

Portanto, o reconhecimento é algo que - compreendido como modelo de intersubjetividade - é exitoso ou pelo menos está referido ao êxito - ou seria ele, vinculado à subjugação, à assimetria e ao necessário desconhecimento do outro, necessariamente destinado ao fracasso? Reconhecimento é condição de possibilidade de liberdade ou de perda de liberdade? Através do reconhecimento podemos encontrar-nos "a nós mesmos" ou o reconhecimento é o meio de um poder estranho ao qual nada de "próprio" se tem a opor?

Nesse ponto, é importante realçar que, para o diagnóstico da subjugação aqui esboçado, não importa com qual orientação temática ou com qual intenção alguém nos influencia da maneira descrita. Já a designação determinante e não apenas o insulto ofensivo, já a influência em si e não apenas a circunstância de que alguém queira me levar a fazer algo que do contrário eu não faria é problemática na perspectiva das teorias por mim aqui esboçadas e exerce o manifesto, o inclusive terrível poder da designação (Butler, 1998, p. 49). Não se trata, pois da demonstração de que ao lado das formas de reconhecimento bem sucedidas também possam existir formas fracassadas, deficitárias ou injuriosas. (Portanto, que uma pessoa possa, por vezes, ser reconhecida por algo pelo qual não deseja ser reconhecida, que lhe seja atribuído algo com que ela não possa identificar-se ou que, de qualquer modo, não absorva). A questão decisiva consiste na tese 
de que essa forma "injuriosa" ou "desconhecedora" do reconhecimento atue como momento constitutivo em todas as relações de reconhecimento.

Para não "subfaturar" as teorias negativas da intersubjetividade, faz-se necessário recordar uma vez mais a questão específica das teorias "negativas". Seu charme melancólico ${ }^{7}$ consiste, propriamente, em que não concebem a influência (reconhecedora) dos outros sobre a própria autocompreensão categoricamente como negativa e restritiva. Ao contrário - e justamente nisso consiste a estrutura aporética da relação -, elas nos veem numa ambiguidade, presos num dilema, que consiste em que aquilo que limita nossa autocompreensão de modo objetivante-reificante seja, ao mesmo tempo, o que a possibilita. Que seja o 'duplo' caráter de possibilitação e subjugação do sujeito (Butler apud Saar 2004, p. 341) (e não, por exemplo, unilateralmente a subjugação) que perfaz a relação de reconhecimento. Analisemos, pois - para poder julgar se a descrição aporética é justificada -, como essa dimensão possibilitadora é descrita.

Nas concepções de reconhecimento de Butler e de Althusser, essa dimensão possibilitadora é elaborada explicitamente: se somente a "interpelação" reconhecedora feita pelo outro me constitui como sujeito, então a "ideologia" do poder de agir do sujeito daí resultante não é apenas, como todas as ideologias, simultaneamente verdadeira e falsa (Adorno, 1972, p. 59); ela é indispensável. Quem poderia querer ficar aquém da unidade ideológica e do poder de agir de sua pessoa (constituídos por interpelação)? Mesmo se o sujeito, como resultado de tal interpelação, for um "fantasma" (como Althusser opina com Lacan), ele é um fantasma até certo ponto necessário, uma ilusão sem a qual não podemos viver $^{8}$. Justamente em consequência das descrições feitas por Butler, essa

\footnotetext{
${ }^{7} \mathrm{~A}$ própria Butler 2001, p. 157ss) se refere à melancolia.

${ }^{8}$ Diferentemente do conceito tradicional, "ideologia" não tem conotação unívoca negativa em Althusser (1977); ou dito de outro modo: ela própria é inevitável.
} 
ambiguidade se torna evidente: nós ansiamos por reconhecimento ainda que sob formas injuriosas, humilhantes ou degradantes - assim ela descreve de modo impressionante -, porque não ser reconhecido implica em levar uma não-existência. Com isso, a dependência do indivíduo do reconhecimento constituinte leva a uma espécie de trama trágica e insolúvel. Tornar-se-pessoa e ser-injuriado ou ser subjugado são dimensões inseparavelmente interligadas de um mesmo processo, que Butler então, consequentemente, designa com o trocadilho "subjetivação", de origem althusseriana/foucaultiana (que significa, simultaneamente, tornar-se sujeito e ser subjugado $)^{9}$.

Também na análise sartreana do olhar reificante há uma ambiguidade constitutiva - mesmo que não admitida. Já vimos que o olhar reificante do outro me fixa, reifica e subjuga. Mas, ao mesmo tempo, somente ele me torna sujeito. Apenas ao perceber-me como objeto da observação do outro, eu me torno "consciente de mim mesmo". Mas, se no contexto da ontologia sartreana, isso significa só assim libertar-se, como sujeito, da fusão com a situação (enquanto, ao contrário, no contexto da famosa situação do buraco da fechadura, ele caracteriza assim a circunstância do ser visto: minha consciência está colada em minhas ações, ela é minhas ações (Sartre, 1994, p. 475), então isso implica que somente o olhar do outro abre, simultaneamente, para mim, um espaço para a ação. Concretamente: apenas quando eu, mediado pelo olhar do outro, me vejo como alguém que espia ciumento pelo buraco da fechadura (e não somente o faço impulsionado por meu ciúme), também posso compreender-me como alguém a quem outras opções estariam disponíveis. Por conseguinte, enquanto, por um lado, o olhar do outro me torna não-livre, ao fixar-me num projeto de ação

${ }^{9}$ Com o intuito de evidenciar uma convergência entre as diferentes teorias negativas do reconhecimento, a leitura dos autores individuais é necessariamente seletiva. Para uma visão abrangente sobre a obra de Butler, ver Redecker (2011). 
e com ele me identificar (agora eu sou o espiador do buraco da fechadura, o ciumento), por outro lado, ele é aquele que me leva a uma compreensão de mim mesmo como alguém que faz isso ou aquilo - e, por isso, também poderia fazer outra coisa. Mas, se isso for verdade, então também aqui as limitações do espaço de possibilidades e sua abertura estão entrelaçadas de modo manifestamente difícil de desemaranhar.

\section{Crítica às teorias negativas da intersubjetividade}

Quem, pois, tem razão? A teoria positiva ou a negativa da intersubjetividade? Ou, dito de outro modo: qual versão "realiza" melhor a percepção decisiva da teoria da intersubjetividade ou da teoria do reconhecimento intersubjetivo (como eu acima adscrevi a ambas versões)?

A tese que ainda quero expor brevemente é: as teorias negativas da intersubjetividade efetivamente veem o caráter possibilitador da relação de reconhecimento. Mas a percepção do duplo caráter do reconhecimento permanece presa a uma dicotomia que ela deveria superar. Já no modo como nelas tanto a possibilitação por um lado como a subjugação e limitação por outro são apresentadas reside um problema conceitual fundamental que faz com que as teses mencionadas permaneçam presas a uma descrição paradoxal-aporética do caráter inevitavelmente social de nossa existência que deveria ser superada. Com isso as teorias negativas da intersubjetividade renunciam à possibilidade de distinguir mecanismos sociais realmente "reificadores" e injuriosos daqueles que para elas são constitutivos, de certo modo embutidos em todo acontecimento reconhecedor ou de cada ato de tornar-se sujeito. Aqui ocorre uma exacerbação do conceito ${ }^{10}$ que não pode fazer qualquer sentido para seu uso social-filosófico.

\footnotetext{
${ }^{10}$ Nesse mesmo sentido, ver Honneth (2004), que aponta para a esterilidade de uma suspeita ideológica generalizada em relação ao reconhecimento.
} 
Aqui somos confrontados com um problema que só pode ser solucionado se a "irrupção do outro" e nosso "desvio através do outro" já for descrita conceitualmente de modo distinto do que o fazem as teorias aqui esboçadas. Efetivamente há nas relações de reconhecimento intersubjetivo um duplo caráter de possibilitação e limitação. E ele naturalmente também leva ocasionalmente àquelas injúrias e desconhecimentos tão precisamente descritos por Butler - a luta por reconhecimento é sempre também uma luta pelo reconhecimento adequado ${ }^{11}$. Mas o duplo caráter em si pode ser resolvido de forma não problemática ou não paradoxal.

Com isso retorno à suspeita já anunciada no início: contrariamente ao seu desejo, as teorias negativas da intersubjetividade por mim descritas e criticadas caem

primeiro: de volta num romantismo residual da subjetividade autêntica que

segundo: ao meu modo de ver anda par e passo com uma compreensão equivocada da relação entre liberdade e determinação e terceiro: elas repousam em última instância sobre uma falsa ontologização da relação de reconhecimento na medida em que não a concebem como uma relação prática.

Sobre o primeiro ponto: embora a constituição fundamentalmente social do sujeito seja afirmada por ambas tradições teóricas e o pressuposto de um self prévio essencial seja rejeitado, na linha de fuga das teorias negativas da intersubjetividade aqui tratadas se revela algo como um romantismo residual da subjetividade autêntica, uma subjetividade portanto que localiza sua autenticidade na esfera (fictícia) de um espaço de autorreferência desimpedida, livre das exigências e cunhações dos outros.

\footnotetext{
${ }^{11}$ Assim, por exemplo, mulheres não querem ser reconhecidas como seres sentimentais, mas como seres racionais; nesse sentido, também classificações reconhecedoras podem ser injuriosas.
} 
Se no entanto (no caso de Judith Butler) o ato da interpelação e o acontecimento do reconhecimento for algo levado ao sujeito a partir de fora, um evento que ele não pode provocar, nem evitar, nem controlar, ${ }^{12}$ então o reconhecimento necessariamente se apresenta como "perda constitutiva" e como "desapropriação". Não é casual que Butler recorre à terminologia da reificação em passagem decisiva. ${ }^{13}$ Quero defender que essa é uma interpretação insuficiente do problema da alienação se com isso se impõe a impressão de que seja o momento da socialização ou da marcação social per se que tem efeito injurioso, reificante, subjugador. ${ }^{14}$ Em O ódio fala, por exemplo, Butler (1998, p. 60) defende que toda designação seja traumática, se antecipe à vontade própria e repita uma subjugação fundamental socialmente marcante. E é precisamente esse o ponto em que ela se afasta da "constatação original" - a saber: no marco da teoria da intersubjetividade - e evoca o antitipo de um self socialmente ileso. Se alguém é aqui desapropriado, não haveria então - contra toda retórica antiessencialista - algo que era próprio do sujeito antes de ele se deparar com o(s) outro(s)? Se o sujeito é desempoderado pelo reconhecimento - então antes disso ele era soberano?

\footnotetext{
${ }^{12}$ Numa tentativa interessante de categorização, Stefan Deines (2007) distinguiu três formas de reconhecimento injurioso em Judith Butler: exclusão, re-desconhecimento e cunhação. No marco de sua pergunta pelas formas da violência social, esta categorização se revela muito útil para a discussão da questão se presumir a possibilidade de um "reconhecimento injurioso" faz sentido para os questionamentos sitemáticos. Para o proceder da própria Butler (e minha crítica a ele) contudo não é desprezível o fato de que ela não faz essas diferenciações e com isso em última instância sugere o caráter fundamental da versão mais abrangente do "reconhecimento injurioso", aquilo que Deines denomina "marcação". Sendo assim, todo reconhecimento seria um reconhecimento injurioso.

${ }^{13}$ De forma análoga, já Rorty (1992, p. 116) havia expressado a suspeita de uma "teoria rudimentar da alienação" em relação a Foucault.

${ }^{14}$ Para mais detalhes a respeito de uma variante não essencialista do conceito de reconhecimento, ver Jaeggi (2005).
} 
Naturalmente que por razões concepcionais os teóricos da intersubjetividade negativa precisam evitar esses antitipos. A habilidade retórica com que justamente Butler consegue manter em (paradoxal) suspense o problema como um luto pela perda de algo do qual ao mesmo tempo se sabe que nunca o possuía não avança o suficiente. E a tentativa tardia de Sartre (1981), de evadir o solipsismo com uma teoria da ação coletiva, permaneceu insuficiente por outras razões. Mas seria demasiado simplório interpretá-lo como recaída em um essencialismo banal (de um self-nuclear não falsificado). Creio antes que o cerne do problema aqui esboçado e a causa das dificuldades por mim apontadas, de conceber a constituição social do self sem sintomas de abstinência filosófica, esteja num conceito de liberdade que pensa a liberdade como indeterminação. Com isso chego ao segundo ponto.

As teorias intersubjetivas da liberdade - e isso é a quintessência da diferença entre modelos positivos e negativos - permanecem presas a um conceito negativo de liberdade, da ("romântica") liberdade como indeterminação, como a presença de possibilidades indeterminadas, e que inclusive contém uma radicalização dramática desta ideia de indeterminação.

Recordemos o que precisamente, na visão das teorias esboçadas, é percebido como expropriante e limitante: o reconhecimento pelo outro me limita porque me furta minhas possibilidades. Face à multiplicidade do que eu poderia ser, o olhar do outro torna-me algo determinado. É portanto uma perda de liberdade como perda de abertura, de fluidez da própria identidade ou de possibilidades da própria existência.

Que feição tem a superação das dicotomias criticadas? Ao invés de contrapor o determinado ao indeterminado (e da identificação de determinação com coerção e indeterminação com liberdade), pode-se estabelecer um vínculo com a seguinte constatação (hegeliana): sem determinação não se é livre - mas indeterminado, portanto, nada determinado 
ou específico. Sem aquilo que Brandon (1979) denomina constraint by norms (e isso de qualquer modo significa: sem determinação social) eu não sou livre, mas incapaz de agir. A pergunta como, por seu turno, é possível tornar-se livre frente a essa normas (e às coerções que podem acompanhá-las) não se coloca mais como alternativa entre determinação e indeterminação (subjugação a essas normas ou liberdade frente a elas), mas como a pergunta pela possibilidade de apropriação e transformação desse ser determinado. Liberdade então não é ausência de determinação e abertura indeterminada, mas transformação apropriante. E a determinação (social) não é uma fronteira externa, mas um material a ser transformado, um ponto de partida inicialmente colocado ou dado, que não obstante (ou só então) pode ser interpretado como "propriamente" nosso. A "diluição de identidade e de formas de identidade" que Butler propaga como o meio para a libertação do sujeito "dos poderes que o tornam possível e (ainda) conformam" nessa perspectiva não é o caminho adequado, porquanto permanece preso às contradições.

Para concluir quero voltar a atenção ainda que brevemente ao terceiro ponto. No início eu havia apontado para o caráter relacional do acontecimento do reconhecimento. Reconhecimento intersubjetivo é algo que se realiza numa relação prática (e até: em disputas práticas e por vezes conflituosas), se constitui praticamente. Ele não é algo ontológico nem uma relação ontológica precedente. As teorias por mim criticadas, ao contrário, se inclinam a ontologizar a relação de reconhecimento. Não está em questão a verdade do sujeito e seu possível desconhecimento, mas sua autonomia, integridade e capacidade para agir e o possível impedimento delas.

A percepção de que aqui se trata de uma relação prática e de uma relação que também subsiste em casos de conflito tem também uma outra faceta: a saber, que também aquelas versões de uma "teoria positiva 
do reconhecimento" que partem de uma espécie de "estar previamente de acordo" (ou do telos da reconciliação) e com isso se tornam cegas para a necessidade de sondar a relação entre dependência e independência na luta por reconhecimento precisam deixar-se recordar que a normatividade e reciprocidade inerentes à relação de reconhecimento só podem ser realizadas no acontecimento real da disputa.

\section{Conclusão: reconhecimento além da reconciliação e subjugação}

Tal como já anunciado, minha conclusão é crítica face à versão negativa; mas também recomenda ao lado positivo que faça jus à "luta" na "luta por reconhecimento", sem exacerbá-la tragicamente ou entendê-la mal agonisticamente.

Por conseguinte, nas discussões acima esboçadas está menos em questão se reconhecimento e sociabilidade são relações conflituosas, senão que a pergunta como se concebe a estrutura interna desse conflito. $\mathrm{E}$ precisamente sobre essa base se pode falar de relações de reconhecimento opressoras e desvirtuadas. A mulher que é reconhecida como um ser natural e sentimental, a pessoa de cor a quem se atribui um sentido de ritmo e uma selvageria incontrolável - os exemplos para reconhecimento que menospreza e limita são muitos. Por isso não é sobejo ter presente que mesmo adscrições positivas podem ser limitantes e injuriosas. Mesmo assim, esses fenômenos seguem sendo exatamente isso: relações fracassadas de reconhecimento, relações que são deficitárias enquanto relações de reconhecimento - e isso não porque reconhecimento por princípio sempre deva fracassar. A crítica a esses fenômenos é central para toda teoria crítica, mas ela não deveria - também não contre coeur - evocar o 
ponto de vista de um sujeito pré e associal na multiplicidade indeterminada de suas possibilidades.

\section{Referências}

ADORNO, Theodor W. Beitrag zur Ideologienlehre. In: ADORNO, Theodor W. Gesammelte Schriften. v. 8. Frankfurt am Main: Suhrkamp, 1972, p. 457-477.

ALTHUSSER, Louis. Ideologie und ideologische Staatsapparate. In: ALTHUSSER, Louis. Ideologie und ideologische Staatsapparate: Aufsätze zur marxistischen Theorie. Hamburg: VSA, 1977, p. 108-153 [Ideologia e aparelhos ideológicos do estado. Lisboa: Presença, 1980.]

BEDORF, Thomas. Verkennende Anerkennung. Frankfurt am Main: Suhrkamp, 2010.

BRANDOM, Robert. Freedom and constraint by norms. American Philosophical Quarterly, v. 16, n. 3, July 1979, p. 187-196.

BUTLER, Judith. Haß spricht: zur Politik des Performativen: Berlim: Berlin Verlag, 1998.

BUTLER, Judith. Psyche der Macht: das Subjekt der Unterwerfung. Frankfurt am Main: Suhrkamp, 2001.

BUTLER, Judith. Kritik der ethischen Gewalt. ed. ampliada. Frankfurt am Main: Suhrkamp, 2007.

CELIKATES, Robin. Unreconciled: where's the struggle in the ,struggle for recognition'? In: BERTRAM, Georg W. et al. (orgs.). Socialité et reconnaissance: grammaires de l'humain. Paris: L'Harmattan , 2007, p. 213-228.

DEINES, Stefan. Verletzende Anerkennung. In: HERRMANN, Steffen Kitty et al. Verletzende Worte. Bielefeld: Transcript, 2007, p. 275-293.

HEGEL, Georg W. F. Phänomenologie des Geistes. Werke 3. Frankfurt am Main: Suhrkamp, 1970 [Fenomenologia do espírito. Petrópolis: Vozes].

HEIDEGGER, Martin. Sein und Zeit. Tübingen: Max Niemeyer Verlag, 1963 [Ser e tempo. Petrópolis: Vozes].

HOBBES, Thomas. Vom Bürger: Elemente der Philosophie II und III. Hamburg: Meiner Verlag, 1994 [Do cidadão. São Paulo: Martins Fontes, 1998].

HONNETH, Axel. Anerkennung als Ideologie. WestEnd: Neue Zeitschrift für Sozialforschung, v. 1, n. 1, 2004, p. 51-70. 
HONNETH, Axel. Kampf um Anerkennung: Zur moralischen Grammatik sozialer Konflikte. Frankfurt am Main: Suhrkamp, 1994 [Luta por reconhecimento. São Paulo: Editora 34].

JAEGGI, Rahel. Entfremdung. Frankfurt am Main: Campus, 2005.

MARKELL, Patchen. Bound by recognition. Princeton: Princeton UP, 2003.

MEAD, Herbert. Geist, Identität und Gesellschaft aus der Sich des Sozialbehaviourismus. Frankfurt am Main: Suhrkamp, 1991.

NEUHOUSER, Frederick. Rousseau's theodicy of self-love: evil, rationality, and the drive for recognition. New York: Oxford University Press, 2008.

REDECKER, Eva von. Zur Aktualität von Judith Butler. Wiesbaden: Verlag für Sozialwissenschaft, 2011.

RORTY, Richard. Kontingenz, Ironie und Solidarität. Frankfurt am Main: Suhrkamp, 1992.

SAAR, Martin. Subjekt. In: Göhler, Gerhard; Iser, Mattias e Kerner, Ina (orgs.). Politische Theorie: 22 umkämpfte Begriffe zur Einführung. Wiesbaden: VS Verlag für Sozialwissenschaften, 2004, p. 332-349.

SARTRE, Jean-Paul. Das Sein und das Nichts: Versuch einer phänomenologischen Ontologie. Reinbek: Rowohlt, 1994 [O ser e o nada. Petrópolis: Vazes].

SARTRE, Jean-Paul. Kritik der dialektischen Vernunft: Theorie der gesellschaftlichen Praxis. Reinbek: Rowohlt, 1981 [Crítica da razão dialética. São Paulo: DP\&a].

Recebido em: 14/03/2013

Aceite final: 05/05/2013 